\title{
Arterial thrombosis in the nephrotic syndrome
}

\author{
Ibrahim H. Fahal, Peter McClelland, Charles R.M. Hay' and Gordon M. Bell
}

The Regional Renal Unit and 'Department of Haematology, Royal Liverpool University Hospital, Prescot Street, Liverpool L7 8XP, UK

\begin{abstract}
Summary: Thrombosis is a frequent cause of morbidity and mortality in patients with the nephrotic syndrome. Venous thrombotic complications are well recognized but arterial complications are rare. Thrombosis is multifactorial, and has been attributed to a hypercoaguable state due to alterations in blood levels of the various factors involved in the coagulation and fibrinolytic systems, alterations in platelet function, venous stasis, haemoconcentration, increased blood viscosity and possibly the administration of steroids. Thrombosis in general and arterial thrombosis in particular is a significant and potentially serious problem in nephrotic patients. Awareness of the condition and its pathogenesis is needed. Assessment for the risk factors is required to allow appropriate prophylactic measures to be taken.
\end{abstract}

\section{Introduction}

Thrombotic complications are common in the nephrotic syndrome. These have been attributed to a hypercoagulable state. ${ }^{1,2}$ Venous thrombosis is well recognized, but arterial thrombosis occurs less frequently and is seen primarily in children. ${ }^{3}$

We report two patients with the nephrotic syndrome who developed arterial thrombosis, and discuss the pathogenesis, management and the prophylaxis of this potentially serious condition.

\section{Case 1}

A 27 year old man with an 18-month history of mesangioproliferative glomerulonephritis and nephrotic syndrome presented with excruciating pain in both lower legs and inability to walk, which began after a long train journey. He smoked about 15-20 cigarettes a day. His only medication was frusemide. Examination revealed that both calves were tender and swollen, and both feet were cold and pale. The pedal pulses were absent. Bilateral leg venography were negative, but bilateral femoral arteriography showed thrombus in both profunda femoralis and distal popliteal arteries.

Investigations showed a protein $\mathbf{C}$ antigen activity of $138 \%(75-155)$. Protein $S$ antigen activity of $82 \%(50-150)$, plasminogen activity of

Correspondence: I.H. Fahal, M.R.C.P., University Department of Medicine, University of Liverpool, PO Box 147, Liverpool L69 3BX, UK.

Accepted: 18 July 1994
$135 \%$ (75-125), fibrinogen $13.1 \mathrm{~g} / 1(1.5-4 \mathrm{~g} / 1)$ and antithrombin III antigen activity of $55 \%(80-155)$. Haemoglobin was $16.5 \mathrm{~g} / \mathrm{dl}$, haematocrit $48.6 \%$, leucocyte count $21.2 \times 10^{9} / 1$, neutrophils $14.8 \times 10^{9} / 1$ and platelet count $318 \times 10^{9} / 1$. Plasma viscosity was $2.14 \mathrm{cp}(1.5-1.72)$ and ESR $115 \mathrm{~mm} /$ 1 hour. Blood urea was $8.3 \mathrm{mmol} / \mathrm{l}$, serum creatinine $95 \mu \mathrm{mol} / 1$, serum albumin $18 \mathrm{~g} / 1$ and with a 24 hours protein excretion of $36 \mathrm{~g}$. Antinuclear antibodies, anti-DNA antibody, anticardiolipin antibodies and lupus anticoagulant were negative. He was treated with analgesia and anti-coagulation with reperfusion of the lower limbs and resolution of the pain. $\mathrm{He}$ was in remission 18 months later.

\section{Case 2}

A 47 year old female with a 6 month history of mesangioproliferative glomerulonephritis and the nephrotic syndrome presented with a painful right leg. She smoked 10 cigarettes a day. Her medications were frusemide and prednisolone. On examination she had cold and blue oedematous feet with absent right femoral, popliteal and pedal pulses. Arteriogram revealed a thrombus causing a complete block in her right iliac inflow together with fairly severe femoro distal occlusive disease.

Investigations revealed a haemoglobin of $15.9 \mathrm{~g} /$ $\mathrm{dl}$, haematocrit $42 \%$ and a leucocyte count $22.4 \times 10^{-9} / 1$, platelets count $420 \times 10^{-9} / 1$. Blood urea was $9.4 \mathrm{mmol} / 1$, serum creatinine $134 \mu \mathrm{mol} / 1$, serum albumin $27 \mathrm{~g} / \mathrm{dl}$ and with a 24 hour protein 
excretion of $18.4 \mathrm{~g}$. Serum cholesterol $17 \mathrm{mmol} / \mathrm{l}$ and triglycerides $10.3 \mathrm{mmol} / \mathrm{l}$. Anti-nuclear antibodies were positive at $800 \mathrm{IU} / \mathrm{ml}$, but antiDNA antibody, anticardiolipin antibodies and lupus anticoagulant were negative. Total protein C antigen activity was $57 \%$, total protein $\mathrm{S}$ antigen activity of $120 \%$, plasminogen activity $110 \%$, fibrinogen $7.42 \mathrm{~g} / \mathrm{dl}$ and anti-thrombin III antigen activity $70 \%$. She underwent a femoro femoral crossover graft operation, removal of the thrombus and was commenced on anti-coagulation with satisfactory reperfusion of her lower limbs. She reached end-stage renal disease 15 months later and commenced haemodialysis.

\section{Discussion}

Thrombosis, a frequent cause of mortality in patients with the nephrotic syndrome, was first reported by Addis in $1948 .{ }^{4}$ Venous thrombotic complications have frequently been observed but arterial complications are rare. ${ }^{5,6}$ In contrast to venous thrombi, which are composed predominantly of fibrin and red cells, arterial thrombi are composed predominantly of platelets. In nephrotic patients, arterial thrombosis has been reported in the aorta, mesenteric, axillary, femoral, ophthalmic, carotid, cerebral, renal, pulmonary and coronary arteries. ${ }^{3}$ The pulmonary ${ }^{8}$ and femoral arteries are particularly susceptible, the latter usually as a complication of attempted blood sampling from the femoral vein. Thrombosis may occur at any stage during the course of the nephrotic syndrome but it is most frequent in the early months.

\section{Factors predisposing to thrombosis}

The tendency of nephrotic patients to develop thrombotic episodes has been attributed to a hypercoagulable state, due to alterations in blood levels of the various factors involved in the coagulation and fibrinolytic systems, alterations in platelet function, venous stasis, haemoconcentration, increased blood visocity, and possibly the administration of steroids.

Blood stasis and hypercoagulability are two important factors for the development of venous thrombosis while arterial hypertension, hyperlipidaemia, tobacco, diabetes and obesity represent further risk factors for arterial thrombosis. ${ }^{9}$

\section{Hypercoagulable state:}

a. Alterations in zymogens and co-factors Several studies showed that the hypercoaguable state is characterized by alterations in the concentrations and activity of a number of coagulation factors. Factors IX, XI and XII are decreased, and appear to be due to their urinary losses due to their small molecular size. ${ }^{10-14}$ In contrast, blood levels of factors II, V, VII, VIII, X and XIII are typically increased. ${ }^{2,15}$ The magnitude of these increases, especially those of the co-factors (factors $\mathrm{V}$ and VIII), correlates with the degree of reduction in serum albumin and is thought to result from increased hepatic synthesis of the factors, stimulated by hypoalbuminemia. ${ }^{14}$

b. Alterations in fibrinogen concentrations An elevation of the plasma fibrinogen levels is a consistent and significant abnormality observed in the nephrotic patients, which is attributed to an increased hepatic synthesis that is proportional to the urinary losses. ${ }^{16} \mathrm{~A}$ number of studies have observed an inverse correlation between fibrinogen concentrations and serum albumin. ${ }^{17}$

c. Alterations in the fibrinolytic system Alterations in the concentrations of several of the components of both the fibrinolytic and anti-thrombin systems have been documented. ${ }^{18}$ Decreased fibrinolytic activity has been associated with hypertriglyceridemia. ${ }^{19}$ Decreased concentrations of plasma plaminogen have been found and are correlated with a low serum albumin and the magnitude of the proteinuria. ${ }^{18}$ Levels of plasminogen activator are elevated. ${ }^{3}$ Levels of alpha 2-anti-plasmin ${ }^{3}$ and alpha 2-macroglobulins ares reported to be increased. ${ }^{20}$

d. Alterations in coagulation inhibitors (physiological anti-coagulants) Plasma concentrations of anti-thrombin III (ATIII) are decreased in the nephrotic syndrome ${ }^{21}$ and its deficiency plays an important role in the development of thrombosis. It is likely that renal losses in nephrotic patients

Changes in coagulation factors and fibrinolysis system in patients with nephrotic syndrome

Increased

Fibrinogen antigen and activity

Factor VIII antigen and activity

Factor XIII antigen

Combined factor II, VII, $\mathrm{X}$ activity

Cofactor $\mathbf{V}$

Alpha 2-macroglobulin

Alpha 2-anti-plasmin

Reduced

Anti-thrombin III

Plasminogen

Factor XI

Factor XII

Areas of controversy

Protein S and protein C (increased in some studies, decreased in others) 
contribute to its deficiency. ${ }^{22,23}$ However, only patients with plasma albumin levels below $20 \mathrm{~g} / 1$ show significant reductions in plasma AT III levels. ${ }^{1}$ A low serum albumin is also correlated with low levels of plasma AT III. ${ }^{1,17}$ Most of these abnormalities tend to normalize with clinical remission of the nephrotic syndrome. ${ }^{24}$ Protein $\mathrm{C}$, a vitamin $\mathrm{K}$-dependent protein, is an anticoagulant that inactivates the coagulation factors V and VIII. Protein $\mathbf{S}$ is a cofactor of activated protein $\mathrm{C}$. The levels of antigenic and functional activity of protein $\mathrm{C}$ have been reported as normal ${ }^{25}$ or raised $^{26}$ in nephrotic patients. On the other hand, raised ${ }^{27}$, normal ${ }^{28}$ and reduced ${ }^{29,30}$ levels of protein $S$ have been reported in nephrotic patients. Major alterations in fluid-phase coagulation proteins and their regulators (such as AT III) seem to be almost confined to severe nephrotic syndromes, with a serum albumin concentration below $20 \mathrm{~g} / \mathrm{dl}$.

e. Alterations in platelet function Thrombocytosis, increased platelets aggregation and adhesiveness, ${ }^{24}$ and an increase in the levels of the plateletrelease substance B-thromboglobulin ${ }^{31,32}$ have been observed in patients with the nephrotic syndrome and may play a role in promoting the hypercoagulable state, and hence the thrombotic complications. ${ }^{33}$ Platelet hyperaggregability correlated with the degree of proteinuria as well as with plasma cholesterol levels. These findings suggest that urinary albumin losses or hyperlipidaemia may be responsible for this platelet hyperaggregability. Platelet aggregability is increased in type II hyperlipoproteinemia to a degree that is comparable to that seen in the nephrotic syndrome. ${ }^{34}$

f. Increased blood viscosity Increased blood viscosity contributes to generation of thromboembolic complications and is due to the haemoconcentration (with elevated values of both haematocrit and haemoglobin concentration), which is often present and aggravated by the therapeutic use of diuretics in these patients. Whole blood viscosity is increased by both the diuretic-related increase in haematocrit and the increased plasma viscosity related to high fibrinogen concentration. ${ }^{35,36}$ When plasma fibrinogen levels increase, especially to

\section{Changes in platelets in patients with the nephrotic} syndrome

Thrombocytosis

Increased adhesiveness

Increased ADP-induced rate and percentage of aggregation

Increased collagen-induced rat and percentage of aggregation

Shorter time for collagen-induced aggregation

Increase in beta-thromboglobulin values as high as $1 \mathrm{~g} / \mathrm{dl}$, as may be seen in nephrotic syndromes, they cause increased erythrocyte aggregation and marked increases in plasma viscosity. ${ }^{35}$

g. Endothelium and atherosclerosis The loss of functional, if not structural, integrity of the vascular endothelium is closely related to the initiation of atherosclerosis. Normal endothelial cells are thrombo-resistant and arterial thrombi characteristically result from elevated shear stress at sites of vascular injury. Shear-induced platelet aggregation is important in physiological haematosis and in the pathogenesis of arterial thrombosis.

Badimon et al $^{37}$ studied the effect of damaged endothelium on the development of atherosclerotic disease. They investigated the function of normal and damaged endothelium in pigs, following superficial balloon injury, which produces a significant alteration in endothelium-dependent coronary vasoreactivity. As vasoconstriction in arteries can reduce blood flow and increase arterial wall-shear forces, which increase platelet deposition in injured arteries, they concluded that the intact endothelium is one of the greatest sources of protection from arterial thrombosis, atherosclerosis and vasoconstriction.

h. Drugs administration Drugs, particularly diurtics $^{17}$ and steroids aggravate the hypercoagulable state in the nephrotic syndrome. Diuretics may enhance volume depletion and thus contribute to the thrombotic phenomena. Steroids administration increases the concentrations of several clotting factors and modifies the coagulation mechanisms. ${ }^{3}$ They raise the concentration of factor VIII ${ }^{38}$ and shorten prothrombin and activated partial thromboplastin times. ${ }^{39}$

\section{Management and thromboprophylaxis}

Thrombosis, a potentially serious problem in nephrotic patients, is multifactorial. A number of predisposing factors has been identified. Anticoagulation therapy should be commenced as soon as the condition is diagnosed. It must be remembered that anti-coagulation in hypoalbuminemic patients is hazardous, higher doses of heparin may be required to achieve a satisfactory anticoagulation, and changes of serum albumin levels may interfere with the anticoagulant effect of warfarin. If the disease remits then anticoagulation can be discontinued after 6 months, otherwise it should be continued until the serum albumin exceeds $20 \mathrm{~g} / \mathrm{dl}$.

\section{Prophylactic anti-coagulation}

Despite the seriousness of this condition, there is no consensus about the need for prophylactic anti- 
coagulation. Bellomo and Atkins ${ }^{40}$ argued the case for prophylactic anti-coagulation in membranous nephropathy and concluded that all nephrotic patients with membranous nephropathy should receive prophylactic anticoagulation therapy unless it is contraindicated.

\section{Aspirin}

There is growing evidence that aspirin may be useful in reducing the risks of thromboembolic disease in the nephrotic syndrome. In a model of arterial thrombosis induced by laser, a partial occlusion was induced in small mesenteric arterioles. Thrombus formed within seconds after the laser lesion and grew rapidly. Embolization began within the minute following the laser flash. The administration of aspirin at three doses $(50,100$ and $200 \mathrm{mg} / \mathrm{kg}$ ) by intramuscular injection, $15 \mathrm{~min}$ before the laser injury, induced three different phenomena: (1) an increase of the number of laser injuries required for the thrombus formation; (2) a dose-dependent decrease in the duration of embolization; and (3) a dose-dependent decrease in the number of emboli. ${ }^{41}$ In another aspirin-sensitive model of arterial thrombosis in anaesthetized rats, carotid artery thrombi were formed in response to electrical stimulation and were occlusive in $84 \%$ of vehicle-treated rats. Among other anti-thrombotic drugs, intravenous administration of aspirin $(10 \mathrm{mg} / \mathrm{kg})$ decreased average thrombus weight by $35 \%$ and also reduced the frequency of occlusion to less than $25 \%{ }^{42}$

\section{Reduction of proteinuria}

Serum albumin below $25 \mathrm{~g} / 1$ is a statistically significant risk factor for venous (40.0 versus $2.7 \%$; $P<0.01)$ and for combined arterial and venous (28.6 versus $5.5 \% ; P<0.01$ ) episodes of thromboembolism. ${ }^{40} \mathrm{~A}$ low serum albumin is inversely correlated with fibrinogen ${ }^{17}$ and correlated with anti-thrombin III, ${ }^{1,17}$ and increased platelet aggregability. These abnormalities can be reduced by the normalization of serum albumin. ${ }^{24}$ An attempt to reduce the degree of proteinuria should be made in these patients. Angiotensin-converting enzyme inhibitors are effective in reducing proteinuria by decreasing glomerular filtration pressure. ${ }^{43}$ Their effect is increased if they are accompanied by a salt-restricted diet. Non-steroidal anti-inflammatory drugs also reduce the proteinuria by reducing the renal blood flow and glomerular filtration rate, ${ }^{44}$ therefore they must not be used in patients with renal impairment.

\section{Drug administration}

Diuretics, the mainstay of therapy in nephrotic oedema should be used with caution and only if oedema persists in spite of salt restriction. The judicious use of salt-poor albumin and diuretic infusion in severe cases reduces the risks of plasma volume depletion, haemoconcentration and thromboembolic complications. Steroid administration increases the concentrations of several clotting factors and modifies the coagulation mechanisms. ${ }^{3}$ Thus these agents should be used cautiously in the treatment of the nephrotic syndrome.

\section{Arterial hypertension}

Arterial hypertension, as discussed earlier, constitutes a risk factor for arterial thrombosis and should be treated vigorously, aiming at a diastolic pressure of less than $90 \mathrm{mmHg}$. Angiotensin-converting enzyme inhibitors are useful in the treatment of hypertension because of their ability to reduce proteinuria and retard progressive glomerular sclerosis.

\section{Hyperlipidaemia}

There is a suggestion that hyperlipidaemia may be responsible for platelet hyperaggregability as platelet aggregability is increased in type II hyperlipoproteinemia to a degree that is comparable to that seen in the nephrotic syndrome. ${ }^{34}$ Reduction of dietary saturated fats and cholesterol, and the administration of the newer and safer anti-lipidaemia drugs, for example, hydroxy-methylglutaryl coenzyme A (HMG CoA) can reverse the nephrotic hyperlipidaemia and thus decrease the platelet hyperaggregability, reducing the risk of thrombosis.

\section{Endothelium and atherosclerosis}

Tobacco, diabetes, and obesity contribute to atherosclerosis. Refraining from smoking, control of weight and diabetes mellitus, if present, is of utmost importance in reducing the risk of atherosclerosis, thus minimizing endothelial damage and possible arterial thrombosis.

Thrombosis in our patients was multifactorial and related partly to the prothombotic tendency associated with a nephrotic syndrome as evident by the low level of anti-thrombin III and the raised fibrinogen level. This is related to the hypoalbuminaemia and the massive proteinuria, particularly in the first patient. Other possible contributing factors to the thrombosis are the hyperlipidaemia and smoking in both patients, the use of diuretics, the stasis and immobility suffered by the first patient during the long train journey, and the use of diuretics and corticosteroids in the second patient. 


\section{Conclusion}

Thrombosis in general and arterial thrombosis in particular is a significant and potentially serious

\section{References}

1. Andrassy, K., Ritz, E. \& Bommer, J. Hypercoagulability in the nephrotic syndrome. Klin Wochenschr 1980, 58: 1029-1034.

2. Kendall, A.G., Loohmann, R.C. \& Dossetor, J.B. Nephrotic sydnrome: a hypercoagulable state. Arch Intern Med 1971, 127: $1021-1027$.

3. Cameron, J.S. Coagulation and thromboembolic complications in the nephrotic syndrome. Adv Nephrol 1984, 13: $75-114$

4. Addis, T. Glomerular Nephritis, Diagnosis and Treatment, Vol. 1. New York, McMillan, 1948.

5. Llach, F. Hypercoagulability, renal vein thrombosis, and other thrombotic complications of nephrotic syndrome. Kidney Int 1985, 28: 429-439.

6. Patel, R. \& Mandal, A.K. Arterial thrombosis associated with the nephrotic syndrome. J Cardiovasc Surg 1978, 19: 129-134.

7. Schafer, A.I. \& Kroll, M.H. Nonatheromatous arterial thrombosis. Annu Rev Med 1993, 44: 155-170.

8. Jones, C.L. \& Hebert, D. Pulmonary thrombo-embolism in the nephrotic syndrome. Pediatr Nephrol 1991, 5: 56-59.

9. Boneu, B. Predisposing factors for thrombosis. Nouv Rev Fr Hematol 1993, 35: 187-190.

10. Handley, D.A. \& Lawrence, J.R. Factor IX deficiency in the nephrotic syndrome. Lancet 1967, 1: 1079-1081.

11. Green, D., Arruda, J., Honig, G. \& Muehrcke, R.C. Urinary loss of clotting factor due to hereditary membranous nephropathy. Am J Clin Pathol 1976, 65: 376-383.

12. Vaziri, N.D., Ngo, J.Ct., Ibsen, K.H., Mahalwas, K., Roy, S. \& Hung, E.K. Deficiency and urinary loss of factor XII in adult nephrotic syndrome. Nephron 1982, 32: 342-346.

13. Natelson, E.A., Lynch, E.C., Hettig, R.A. \& Alfrey, C.P Acquired factor IX deficiency in the nephrotic syndrome. Ann Intern Med 1970, 73: 373-378.

14. Vazini, D., Ngo, J.C.T., Ibsen, K.H., Mahalwask, K., Roy, S. \& Hung, E.K. Deficiency and urinary loss of factors XII in adult nephrotic syndrome. Nephron 1982, 32: 342-346.

15. Kanfer, A., Kleinknetch, D., Broyer, M. \& Josso, F. Coagulation studies in 45 cases of nephrotic syndrome without uremia. Thromb Diathes Haemorrh 1970, 24: 562-571.

16. Takeda, Y. \& Chen, A. Fibrinogen metabolism and distribution in patients with the nephrotic syndrome. J Lab Clin Med 1967, 70: 678-685.

17. Robert, A., Olmer, M., Sampol, J., Gugliotta, J.E. \& Casanova, P. Clinical correlation between hypercoagulability and thromboembolic phenomena. Kidney Int 1987, 31: $830-835$.

18. Scheinman, K.I. \& Stiehm, E.R. Fibrinolytic studies in the nephrotic syndrome. Paediatr Res 1971, 5: 206-212.

19. Simpson, H.C.R., Mann, J.I., Meade, I.W. et al. Hypertriglyceridaemia and hyercoagulability. Lancet 1983, i $786-789$.

20. Thomson, C., Forbes, C.D., Prentice, C.R. et al. Changes in blood coagulation and fibrinolysis in the nephrotic syndrome. $Q J$ Med 1974, 43: 399-407.

21. Kauffmann, R.H., Veltkamp, J.J. \& van Tilburg, N. Acquired antithrombin III deficiency and thrombosis in the nephrotic syndrome. Am J Med 1978, 65: 607-610.

22. Varizi, N., Paule, P. \& Tookey, J. Acquired deficiency and urinary excretion of antithrombin III in nephrotic syndrome. Arch Intern Med 1984, 144: 1802-1803.

23. Thaler, E., Blazer, E., Kopsa, H. \& Pinggera, W. Acquired antithrombin III deficiency in patients with glomerular proteinuria. Haemostasis 1978, 7: 257-272.

24. Remuzzi, G., Mecca, G., Marchest, D., Liuis, M., Gaetano, G., Donati, M.B. \& Silver, M.J. Platelet hyperaggregability and the nephrotic syndrome. Thromb Res 1979, 16: 345-354 problem in nephrotic patients. Awareness of the condition is needed. Assessment for the risk factors is required to allow appropriate prophylactic measures to be taken.

25. Soff, G.A., Sica, D.A., Marlar, R.A., Evans, H.J. \& Qureshi, G.D. Protein $C$ levels in nephrotic syndrome: use of a new enzyme-linked immunoadsorbent assay for protein C. $\mathrm{Am} \mathrm{J}$ Haematol 1985, 22: 43-49.

26. Cosio, F.G., Harker, C., Batard, M.A., Brandt, J.T. \& Griffin, J.H. Plasma concentrations of the natural anticoagulants protein $\mathrm{C}$ and protein $\mathrm{S}$ in patients with proteinuria. J Lab Clin Med 1985, 106: 218-222.

27. Vaziri, N.D., Alikhani, S., Patel, B., Nguyen, Q., Barton, C.H. \& Gonzales, E.V. Increased levels of protein $\mathrm{C}$ activity, protein $\mathrm{C}$ concentration, total and free protein $\mathrm{S}$ in nephrotic syndrome. Nephron 1988, 49: 20-23.

28. Gouault-Heilmann, M., Gadelha-Parenete, T., Levent, M. et al. Total and free protein $\mathrm{S}$ in nephrotic syndrome. Thromb Res 1988, 49: 37-42.

29. Vigano-D'Angelo, S., D'Angelo, A., Kaufman, C.E. et al. Protein $\mathrm{S}$ deficiency occurs in the nephrotic syndrome. Ann Intern Med 1987, 107: 42-47.

30. Garbrecht, F., Gardner, S., Johnson, V. \& Grabowski, E Deep venous thrombosis in a child with nephrotic syndrome associated with a circulating anticoagulant and acquired protein S deficiency. Am J Paediatr Haematol Oncol 1991, 13: 330-333.

31. Alder, A.J., Lundin, A.P. \& Feinroth, A.P. Beta thromboglobulin levels in the nephrotic syndrome. Am J Med 1980 , 69: $551-554$.

32. Andrassy, K., Depperman, D., Walter, E., Koderish, J., Ritz, E. \& Post, P. Is beta thromboglobulin a useful indicator of thrombosis in nephrotic syndrome? Thromb Haemost 1979 , 42: $485-490$.

33. Llach, F. Thromboembolic complications in nephrotic syndrome. Postgrad Med 1984, 76: 111-123.

34. Carvalho, A., Colman, R. \& Lees, R. Platelet function in hyperlipoproteinemia. N Engl J Med 1974, 290: 434-439.

35. Ozanne, P., Francis, R.B. \& Meiselman, H.J. Red blood cell aggregation in nephrotic syndrome. Kidney Int 1983, 23: 519-525.

36. McGinley, E., Lowe, G.D.O., Boulton-Jones, M., Forbes, C.D. \& Prentice, C.R.M. Blood viscosity and haemostasis in the nephrotic syndrome. Thromb Haemost 1983, 49: 155- 157 .

37. Badimon, J.J., Penny, W., Webster, M.W., Chesebro, J.H. \& Fuster, V. Endothelium and atherosclerosis. J Hypertens 1992, 10 (Suppl): S43-S50.

38. Ozsosylu, S., Strauss, H.S. \& Diamond, L.K. Effects of corticosteroids on coagulation of the blood. Nature 1962 , 196: $1214-1215$.

39. Ueda, N. Effects of corticosteroids on coagulation factors in children with nephrotic syndrome. Paed Nephrol 1987, 1: 286-289.

40. Bellomo, R. \& Atkins, R.C. Membranous nephropathy and thromboembolism: is prophylactic anticoagulation warranted? Nephron 1993, 63: 249-254.

41. Vesvres, M.H., Doutremepuich, F., Lalanne, M.C. \& Doutremempuich, C. Effects of aspirin on embolization in an arterial model of laser-induced thrombus formation Haemostasis 1993, 23: 8-12.

42. Schumacher, W.A., Heran, C.H., Steinbacher, T.E. et al. Thrombin inhibition compared with other antithrombotic drugs in rats. Thromb Res 1992, 68: 157-166.

43. Heeg, J.E., de Jong, P.E., van der Hem, G.K. et al. Efficacy and variability of the antiproteinuric effect of $A C E$ inhibition by lisinopril. Kidney Int 1989, 36: 272-275.

44. Bergstein, J.M. Prostaglandin inhibitors in the treatment of nephrotic syndrome. Pediatr Nephrol 1991, 5: 335-339. 